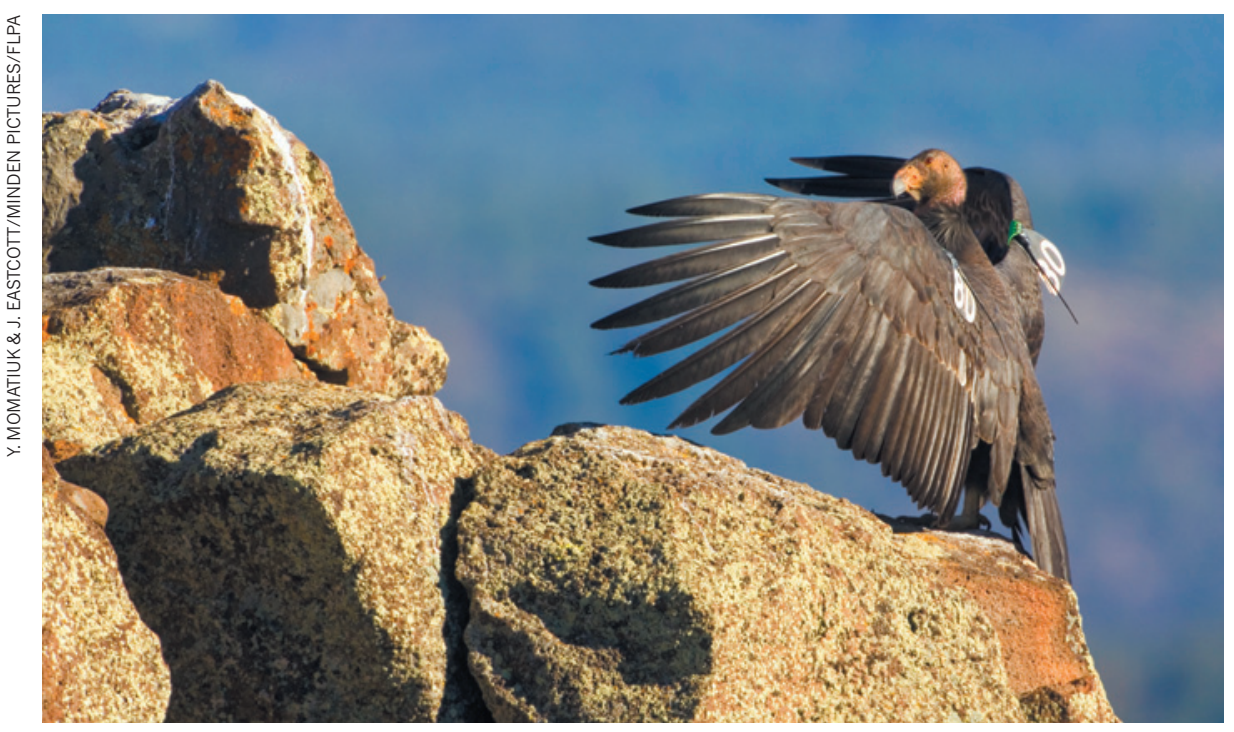

Despite a ban on toxic bullets, the carcasses left by US hunters are poisoning this majestic carrion feeder.

SPECIES RECOVERY

\title{
California condors face lead menace
}

\section{Signature species may need perpetual conservation.}

\section{BY MEERA SUBRAMANIAN}

$\mathrm{A}$ fter more than three decades on the brink of extinction, the California condor (Gymnogyps californianus) - the largest and most threatened wild bird species in the United States - is making a modest recovery, thanks to intensive captive breeding and medical intervention. But troubling data reported this week suggest that unless hunters change their practices, the condor will require extensive support in perpetuity if it is to survive in the wild.

The cause of the problem is that the condors ingest lead when they feed on the carcasses of animals that hunters have shot. A multidisciplinary study published on 26 June (M. Finkelstein et al. Proc. Natl Acad. Sci. USA http:// dx.doi.org/10.1073/pnas.1203141109; 2012) shows that chronic lead poisoning persists among condors, despite a 2008 California ban on the use of lead shot in regions where the birds are being reintroduced.

Building on earlier studies, the researchers collected feathers and blood samples from trapped birds and found no discernible difference in lead levels before and after the ban. Condors feed by scavenging; the results show that many of those sampled have dangerous levels of lead in their bodies. Lead poisoning can severely damage the birds' nervous systems and impair liver and kidney function, among other problems, and it can be fatal. The study also found that approximately $20 \%$ of condors in the wild have lead levels that are high enough to require costly treatment with chemical agents to remove the toxic metal from their bodies.

"By any measure, the lead poisoning rates in condors are of epidemic proportions," says Myra Finkelstein, a toxicologist at the University of California at Santa Cruz, who led the research

The California condor population fell to an all-time low of 22 individuals in 1982, but captive-breeding and monitoring programmes have brought it back up to nearly 400 birds. Of

\section{LOADED ODDS}

A condor is likely to be poisoned even if just a small proportion of the carcasses it consumes contain lead.

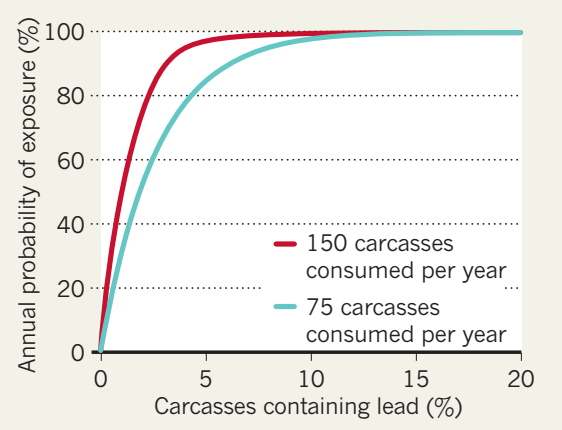

those, half reside in captive-breeding centres, which provide a steady supply of new releases. In California, only 24 chicks have fledged in the wild. At that rate, the study shows, it would take 1,800 years for the population in California to reach 150 - the number called for in the recovery plan - without the ongoing release of birds bred in captivity.

Finkelstein's team did an isotopic analysis of the lead in the birds and identified lead shot or bullets as the main source of contamination. Even though hunters must use copper bullets or other alternatives in condor habitat, some are apparently ignoring the ban. Condors must consume $75-150$ carcasses every year to maintain a healthy weight. The study found that even if fewer than $2 \%$ of the carcasses contain lead, there is a $50 \%$ chance that a condor will eat contaminated meat (see 'Loaded odds').

"Kudos to the hunters who are using copper [bullets], but it isn't going to be effective until you get all the lead out," says Jeff Miller, conservation advocate for the Center for Biological Diversity (CBD), based in Tucson, Arizona. Lead ammunition is cheaper and popular with hunters. The American Bird Conservancy in The Plains, Virginia, which advocates for leadfree hunting, argues that publicizing the risk of lead shot to human health might persuade hunters to use alternatives.

Pedro Nava, a former member of the California State Assembly who spearheaded the lead ban, says that a lack of resources for enforcing the ban means that the condor's future depends on the good will of hunters. He says that the California Department of Fish and Game needs more enforcement personnel. "They have 300 game wardens in the state. If they were to be consistent with other states in terms of population, they should have a thousand," he says.

Nava says that he would like to see the ban expand beyond condor habitat, starting with state-owned uplands favoured by hunters. On 7 June, the CBD filed a lawsuit to require the US Environmental Protection Agency (EPA) to ban lead ammunition, but the agency maintains that it lacks the legal authority to do so.

Despite general acceptance in the United States for the need to restrict lead in nearly all commercial products, the National Rifle Association (NRA), based in Washington DC, says that applying such rules to ammunition would infringe US gunowners' rights. "We'd look at it as an anti-gun move," said Susan Recce, the NRA's director of conservation, wildlife and natural resources. The NRA is lobbying for legislation that would prevent any EPA intervention.

Finkelstein says that the problem has to be addressed somehow, or the California condors will never recover. "We're spending an exorbitant amount of time tracking, trapping and hospitalizing these condors to manage their lead poisoning episodes," she says. "It's just not an effective way to go about this problem." - 